\title{
Choosing Sport Management as a College Major
}

\author{
Keri A. Schwab \\ California Polytechnic University \\ Daniel Dustin \\ Eric Legg \\ Danielle Timmerman \\ Mary Sara Wells \\ University of Utah \\ Skye G. Arthur-Banning \\ Clemson University
}

\begin{abstract}
The purpose of this study was to better understand sport management students within departments of parks, recreation, and tourism, and to address the often uneasy fit faculty experience when trying to educate sport and recreation students in the same classes. Researchers sent a 16-item online questionnaire to 1,337 undergraduate sport management majors at seven universities offering sport management as an emphasis within a department of parks, recreation, and tourism. Results yielded a $32 \%$ response rate, and indicated many similarities among the seven universities. The results also provided guidance for addressing the challenges faced by parks, recreation, and tourism educators when teaching students who identify with sport rather than recreation, and who are highly focused on a career in sport. The article concludes with implications for advising, curriculum planning, and employment potential.
\end{abstract}

Keywords: Sport management; parks, recreation, and tourism education; career choice; career preparation; academic advising

Keri Schwab is an assistant professor in the Recreation, Parks, and Tourism Administration Department at California Polytechnic University, San Luis Obispo, Daniel Dustin is a full professor, Eric Legg and Danielle Timmerman are graduate assistants and Mary Sara Wells is an assistant professor in the Department of Parks, Recreation, and Tourism at the University of Utah.

Skye Arthur-Banning is an associate professor in the Department of Parks, Recreation and Tourism Management at Clemson University.

Please address all correspondence to Keri A. Schwab, Ph.D., Recreation, Parks, and Tourism Administration Department, California Polytechnic University, San Luis Obispo, CA 93407. Email: keschwab@calpoly.edu 
The proliferation of sport management degree programs in colleges and universities during the past quarter of a century has been staggering. According to the North American Society for Sport Management (NASSM, 2012), there are now well over 300 such degree programs in the United States (U.S.). This growing interest in sport as a career track has paralleled a growing interest in sport throughout society. Sport is brought into our lives on a daily basis via television, children are introduced to a variety of sports through informal play, organized leagues, and public and private schools during their formative years, and social media provide constant reminders of the importance of sport to social and cultural identity. Increasingly, U.S. youth are becoming what might be called the "ESPN Generation."

While sport management degree programs are housed in a variety of academic departments, including business, kinesiology, exercise and sport science, and physical education, many of them are housed in departments of parks, recreation, and tourism (Edwards \& Peachey, 2010). The appropriateness of the fit between sport management and parks, recreation, and tourism has received increasing attention in the literature during the past five years (Chalip, Schwab, \& Dustin, 2010; Dustin \& Schwab, 2008a, 2008b; Edwards \& Peachey, 2010; Gibson, 2008; Howard, 2008; McDonald, 2008; Wellman \& Rea, 2008). While Dustin and Schwab have been critical of the arrangement (2008a, 2008b), Howard (2008), Chalip (2009), and Edwards and Peachey (2010), in particular, have taken a more positive view of the two fields' complementary potential.

Part of the problem with including sport management under the umbrella of a parks, recreation, and tourism department is that these departments do so under the impression that sport management can be taught as if it were just another emphasis within parks, recreation, and tourism (Dustin \& Schwab, 2008a, 2008b). Instead, sport management students identify strongly with sport, not recreation, and expect their education to focus on sport. Exacerbating the situation is the fact that in many departments of parks, recreation, and tourism, faculty members are ill-equipped by education or experience to accommodate the professional interests of sport management students. The students receive a general management-oriented education that requires them to apply what they learn to the context of sport. This can result in a highly problematic teaching and learning environment for sport management students and the parks, recreation, and tourism faculty members who serve them.

Those who see the relationship as beneficial have a different point of view. Edwards and Peachy (2010), for example, contend that sport management and parks, recreation, and tourism share a common academic heritage, and building on that heritage can lead to a complementary academic future. They reason further that even though many sport management students show a great interest in working on the business oriented ("sport as entertainment") rather than the recreation oriented ("sport as participation") side of sport, there is much collaborative potential if sport management students and parks, recreation, and tourism faculty work together (Chalip, 2009; Edwards \& Peachey; Howard, 2008; Gibson, 2008; McDonald, 2008; Wellman \& Rea, 2008).

While the debate continues regarding the best academic home for sport management students, an important factor has yet to be explored. Little research has been conducted on sport management students themselves to determine their backgrounds, career aspirations, and attitudes about their chosen major. ${ }^{1}$ In particular, what explains their passion for sport? How did they discover and why did they choose sport management as their major? What are their career aspirations and how informed are they about professional opportunities? Furthermore, what do they believe is the role of sport in U.S. culture and what is the relationship between sport and recreation?

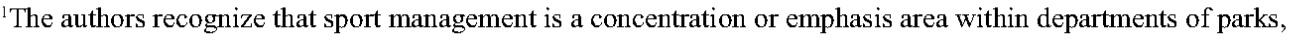
recreation, and tourism. However, students usually identity with sport management as their 'major,' thus, we will refer to it as a major in this paper. 
The purpose of this study was to address the underlying questions of who sport management students are and what their career aspirations might be. Answers to these questions could provide a better foundation for helping educators understand how sport management students fit or do not fit into departments of parks, recreation, and tourism, as well as provide guidance for making the relationship between sport and parks, recreation, and tourism more harmonious.

\section{Methods}

To address these questions, researchers designed a 16-item questionnaire intended to probe four areas, determined a priori, that can influence college major choice: students' backgrounds, interests, personalities, and career aspirations. The instrument is reproduced in Table 1 . All questions were closed-ended with multiple response options provided, including several questions with an option of "other," to which respondents could add additional information. A number of questions asked participants to select all responses that applied to them, thus the total of some responses is greater than $100 \%$. The questionnaire was reviewed by a panel of experts, including sport management faculty from two universities and faculty members whose primary focus is undergraduate education. Questions 1, 2, 4, and 15 were intended to better understand students' backgrounds, items 6 and 7 were aimed at learning about their choice of a major, questions $5,8,9$, and 10 sought to understand their career aspirations, and items $11,12,13$, and 14 were intended to gauge their thoughts on the significance of sport in U.S. life.

The research team sent the questionnaire electronically to contacts at seven universities offering a sport management emphasis as part of a larger department of parks, recreation, and tourism (North Carolina State University, Florida International University, Clemson University, the University of Illinois, Indiana University, the University of Florida, and the University of Utah). The contacts agreed to forward the online survey link to all of their currently enrolled undergraduate sport management students. These universities are representative of a larger population of institutions offering sport management as part of their undergraduate curricular offerings in departments of park, recreation, and tourism.

The research team followed the Tailored Design Method (TDM) for online questionnaire distribution (Dillman, Smyth, \& Christian, 2009). The TDM is considered the standard for conducting electronic surveys in the social sciences and following it can lead to increased response rates as well as elimination of common sources of error in survey research. Following TDM protocol, the research team sent an advance notice email to contacts at each of the participating universities describing the need for, and purpose of, the survey. The university contacts forwarded the notice to all of their currently enrolled undergraduate sport management students. One week later, the research team followed the same procedure to distribute an electronic cover letter along with a link to the online questionnaire. After two weeks, researchers asked the contacts to send a follow-up email thanking students who had already responded and requesting a response from those who had not. Two weeks after that, the contacts sent another thank you email and a final reminder to all remaining potential participants with an announcement of the survey's final closing date. The questionnaire was available for six weeks. A total of 1,337 students across the seven universities received the questionnaire and researchers received 434 completed responses resulting in a $32 \%$ response rate.

\section{Results}

Descriptive statistics for each of the questions were calculated for analysis purposes. Additionally, cross tabulations were conducted in order to explore relationships among certain variables of interest (David \& Sutton, 2004). Results from the questionnaire were fairly consistent across universities 


\section{Table 1}

\section{Choosing Sport Management as a College Major Questionnaire}

\begin{tabular}{|c|c|}
\hline Question & Multiple Choice Response Options \\
\hline $\begin{array}{l}\text { Question 1: When you were growing up, how active were you } \\
\text { in playing sports? }\end{array}$ & $\begin{array}{l}\text { Very active } \\
\text { Active } \\
\text { Somewhat active } \\
\text { Not active at all }\end{array}$ \\
\hline $\begin{array}{l}\text { Question 2: To what extent would you say you are a sports } \\
\text { fan? }\end{array}$ & $\begin{array}{l}\text { I'm a die-hard sport fan } \\
\text { I'm a casual sport fan } \\
\text { Hardly } \\
\text { Somewhat }\end{array}$ \\
\hline $\begin{array}{l}\text { Question 3: To what extent would you say your identity is } \\
\text { wrapped up in sports? }\end{array}$ & $\begin{array}{l}\text { Completely } \\
\text { A lot } \\
\text { Somewhat } \\
\text { Not at all }\end{array}$ \\
\hline Question 4: Are you a varsity athlete in college? & $\begin{array}{l}\text { Yes } \\
\text { No }\end{array}$ \\
\hline $\begin{array}{l}\text { Question 5: At which level of sport are you primarily } \\
\text { interested in working? (select all that apply) }\end{array}$ & $\begin{array}{l}\text { Collegiate Sports } \\
\text { High School Sports } \\
\text { Intramural Sports } \\
\text { Community-based } \\
\text { Professional }\end{array}$ \\
\hline $\begin{array}{l}\text { Question 6. How did you learn about the sport management degree } \\
\text { option? }\end{array}$ & $\begin{array}{l}\text { Academic Advising (high school or college advisor) } \\
\text { Course Catalog } \\
\text { From watching sports on television } \\
\text { From a parks, recreation, and tourism department } \\
\text { website } \\
\text { From someone who works in the sport or recreation } \\
\text { fields } \\
\text { From own work in the field } \\
\text { Other, please specify }\end{array}$ \\
\hline $\begin{array}{l}\text { Question 7: Why did you choose to study sport management? } \\
\text { (select all that apply) }\end{array}$ & $\begin{array}{l}\text { I enjoy playing sports } \\
\text { I enjoy watching sports } \\
\text { I love sports and want to work in the industry } \\
\text { I want to run community-based sports programs } \\
\text { I am interested in the issues revolving around sport } \\
\text { There are many job opportunities in sport management } \\
\text { Other, please specify }\end{array}$ \\
\hline $\begin{array}{l}\text { Question 8: What aspects of sport management appeal to you? } \\
\text { (select all that apply) }\end{array}$ & $\begin{array}{l}\text { Marketing } \\
\text { Public Relations } \\
\text { Personnel Management } \\
\text { Retail } \\
\text { Coaching } \\
\text { Athletic Administration } \\
\text { Recreational Sport Programming } \\
\text { Other, please specify }\end{array}$ \\
\hline $\begin{array}{l}\text { Question 9: How confident are you that you understand the } \\
\text { career opportunities available to you with a focus on sport } \\
\text { management? }\end{array}$ & $\begin{array}{l}\text { Very confident } \\
\text { Somewhat confident } \\
\text { Confident } \\
\text { Not confident }\end{array}$ \\
\hline $\begin{array}{l}\text { Question 10: What is your career goal after completing your } \\
\text { sport management studies? }\end{array}$ & $\begin{array}{l}\text { Athletic Administration } \\
\text { MBA/Attend graduate school } \\
\text { International sports career } \\
\text { Professional sport job } \\
\text { Coaching } \\
\text { Law School } \\
\text { Community recreation } \\
\text { Commercial or Private recreation } \\
\text { Collegiate sport job } \\
\text { Community relations for professional or collegiate } \\
\text { sports } \\
\text { Human Resources for a sports organization } \\
\text { Don't know } \\
\text { Other, please specify }\end{array}$ \\
\hline
\end{tabular}


Table 1 (cont).

\begin{tabular}{|c|c|}
\hline $\begin{array}{l}\text { Question 11: In your opinion, which of the following is the } \\
\text { most accurate statement about the significance of sport in } \\
\text { contemporary American life? }\end{array}$ & $\begin{array}{l}\text { Sport is a critical source of social and cultural identity } \\
\text { Sport reflects the essence of what life is about } \\
\text { Sport is a great vehicle for youth development } \\
\text { Sport is primarily a business } \\
\text { Sport is largely a diversion from life's more serious side }\end{array}$ \\
\hline $\begin{array}{l}\text { Question 12: With regard to sport as participation (active } \\
\text { involvement in playing a sport) and sport as entertainment } \\
\text { (watching sporting events), which do you believe is more } \\
\text { important to our culture? }\end{array}$ & $\begin{array}{l}\text { Sport as participation } \\
\text { Sport as entertainment }\end{array}$ \\
\hline $\begin{array}{l}\text { Question 13: Do you believe that sport receives too much } \\
\text { emphasis, not enough emphasis, or the right amount of } \\
\text { emphasis in our culture? }\end{array}$ & $\begin{array}{l}\text { Not enough emphasis } \\
\text { The right amount of emphasis } \\
\text { Too much emphasis }\end{array}$ \\
\hline $\begin{array}{l}\text { Question 14: How do you see the relationship between sport } \\
\text { and recreation? }\end{array}$ & $\begin{array}{l}\text { Sport is a specialization within recreation } \\
\text { Recreation is a specialization within sport }\end{array}$ \\
\hline Question 15: What is your sex? & $\begin{array}{l}\text { Male } \\
\text { Female }\end{array}$ \\
\hline Question 16: In what university are you now enrolled? & $\begin{array}{l}\text { University of Utah } \\
\text { Florida International University } \\
\text { Indiana University (Dept. of Parks, Recreation \& } \\
\text { Tourism Studies) } \\
\text { University of Florida } \\
\text { University of Illinois } \\
\text { North Carolina State University } \\
\text { Clemson University }\end{array}$ \\
\hline
\end{tabular}

with the exception of responses from one university on one item. The majority of the results are discussed as a group, with the exception of that particular item. As noted above, the 16 items on the questionnaire were grouped a priori into four thematic areas and are relabeled here to better illustrate those themes: 1) portrait of sport management students, 2) choosing sport management as a college major, 3) career aspirations in sport management, and 4) the significance of sport in U.S. life.

\section{Portrait of Sport Management Students}

Sport management students tend to be overwhelmingly male ( $70 \%$ vs. $30 \%$ female) and very few are involved in varsity athletics at the collegiate level (13\%). However, sport still plays a significant role in most participants' lives. When considering the role of sport in their formative years, $96 \%$ said they were either "active" or "very active" in sports (18\% and $78 \%$ respectively). In addition to participation levels, respondents were also highly involved in sport from an entertainment perspective with $78 \%$ considering themselves "die-hard" sports fans. Furthermore, the identity of most participants was closely connected to sport as $79 \%$ felt their identities were wrapped up in sport either "a lot" (55\%) or "completely" (24\%). This presents a picture of sport management students who strongly identify with, and are highly interested in, sport as a result of an active history and connection to sports fandom. This portrait is even more pronounced when looking at relevant relations among these questions. For example, cross tabulations indicated that $81 \%$ of respondents who said they were "very active" playing sports also stated they were "die-hard" sports fans, and $84 \%$ of respondents who were "very active" in sports said their identity was either "a lot" or "completely" wrapped up in sports.

\section{Choosing Sport Management as a College Major}

Two items on the questionnaire addressed the issue of how students selected sport management as their major. The first item focused on discovering sport management and the second on choosing it. When it came to finding out about sport management, results suggested that sport management, like many other professional degree tracks, is a discovery major. Overall, most students learned about this opportunity from course catalogues (32\%) or from their high school or college academic advisors 
(26\%). Other students heard about sport management from friends (14\%), through television (8\%), or academic websites (7\%).

Once they heard about sport management, students tended to have multiple reasons for selecting it as their major. A vast majority chose sport management because they loved sports and wanted to work in the industry (89\%), enjoyed watching sports, $(69 \%)$ or enjoyed playing $(67 \%)$ sports. Others said they were interested in issues revolving around sports (48\%). Many students reported an interest because of the many perceived job opportunities in sports (39\%) or due to an interest in communitybased programming (16\%). Students who were very active in playing sports were also much more likely to choose sport management as their major because they enjoyed playing sports or because they loved sports. Ninety-one percent (91\%) of students who were "very active" playing sports also stated they chose sport management as a major because they loved sports and $71 \%$ of those who were "very active" stated they chose sport management because they enjoyed playing sports. This is in contrast to students who were only "somewhat active" in playing sports. For these students, the most popular reason for choosing sport management as a major was because they enjoyed watching sports $(76 \%)$.

\section{Career Aspirations in Sport Management}

Responses to items regarding career aspirations were slightly more varied across universities. Students were first asked what areas in sport management appealed to them, and their responses revealed a variety of interests. Seventy percent $(70 \%)$ reported an interest in athletic administration, $62 \%$ in personnel management, $57 \%$ in marketing, $47 \%$ in public relations, $42 \%$ in coaching, $32 \%$ in recreational sport programming, and $18 \%$ in retail.

The biggest difference among reporting universities was in response to an item asking about participants' career goals. For six of the seven universities, responses were fairly consistent with an overwhelming preference for careers at elite levels of sport (and that would likely require higher levels of education). For these six schools, $41 \%$ of respondents stated they would like to earn either a law or other advanced degree, or work in professional or international sport. In comparison, less than $10 \%$ were either undecided or wanted to work in community focused sport management. At Clemson University, however, more students were undecided regarding career aspirations (33\%), while only $19 \%$ aimed to earn an advanced degree or work at an elite level. This could be due to a difference in faculty expertise at Clemson, departmental connections in the community, or Clemson's setting and student population in general. Further investigation is required before making inferences as to the source of this difference.

One of the more prominent relations was between career aspiration and identity. Once again, cross tabulations revealed that $70 \%$ of respondents who stated their identity was completely wrapped up in sports also expressed an interest in coaching. Of the remaining categories, the next highest relation between identity and coaching was between respondents who stated that their identity was wrapped up in sports "a lot." For this group, however, only $38 \%$ expressed an interest in coaching, further demonstrating that an interest in a coaching career is strongly associated with an identity that is wrapped up in sports.

Although there was considerable variety in what types of careers the sport management students desired, they were more consistent in their understanding of available career opportunities. Overall, $64 \%$ were either "confident" or "very confident" that they understood career opportunities available to them in the sport management field ( $46 \%$ and $18 \%$ respectively). Much lower numbers reported feeling only "somewhat confident" (32\%) or "not confident" (4\%) in their understanding of available career options. 


\section{The Significance of Sport in U.S. Life}

The final theme concerns student perceptions of the role of sport in U.S. life. Participants in this study tended to feel that sport was of critical importance for a variety of reasons. The majority of participants (54\%) felt the primary reason for that importance was because sport is a source of social and cultural identity. Fewer students believed this critical importance to U.S. life was because sport was a great vehicle for youth development (14\%), sport reflected the essence of what life is about (12\%), or because sport was a diversion from life's more serious side (10\%). A small portion also believed that sport's primary role was as a business (10\%).

The perceived importance of sport was also revealed in an item that asked whether or not respondents felt sport was over or under emphasized in U.S. culture. Among sport management students, the vast majority believed sport either received the right amount of emphasis (67\%) or not enough (19\%), while only $14 \%$ believed sport was too highly emphasized.

In what may be the most interesting findings in this thematic area, the relationship between recreation and sport was somewhat contradictory to the career aspirations of most respondents. Despite the fact that the greatest numbers of sport management students wanted to work at elite levels, approximately $58 \%$ believed that greater importance lay in playing sports rather than watching them. In addition, most participants (70\%) stated that they believed sport management was a specialization within recreation as opposed to $26 \%$ who felt recreation was a specialization within sport. Only $4 \%$ believed the two were unrelated.

\section{Discussion}

The purpose of this study was to better understand the backgrounds, interests, and aspirations of undergraduate sport management students housed in academic departments of parks, recreation, and tourism. The need for the study was prompted by what the researchers perceived to be an uncomfortable fit between parks, recreation, and tourism faculty members and the increasing numbers of sport management students in such departments. Although the results of the study do not directly answer the question of fit, knowing more about sport management students in parks, recreation, and tourism departments does offer insight into how faculty members can better serve students. For discussion purposes, the results are categorized into four topics: selecting a college major, advising newly declared majors, curricular implications, and employment implications.

\section{Selecting a College Major}

The literature suggests that it should not be surprising that students who identify strongly with and have a passion for sport would choose sport management as their college major. Sibson (2010), for example, reports that "lifestyle, personal interest, and previous exposure to sport may be important in student choices of courses" (p. 384). In the career counseling literature, Holland's Theory of Vocational Choice echoes this sentiment by suggesting that students will choose professions in which they believe the work will match their personality (Holland, 1973). Additional research supporting these claims suggests that a positive match between personality and work environment can increase job satisfaction, and that there is likely a positive correlation between job and life satisfaction (Nicademus, 2012). The literature supports the logic that students will choose a career that matches their personality, as they will likely experience greater job and life satisfaction. Based on the results reported here, sport management students appear to be doing what is in their best interests by choosing a major that matches their personality.

At the same time, results from this study suggest sport management students may not have given much thought to career opportunities before choosing a major. They selected their major based 
on a love for sport and a desire to do something with their lives that allowed them to be close to sport. Indeed, when asked to identify career aspirations, students provided a variety of responses and seemed optimistic about their ability to attain career goals. Yet when asked to specify such career goals, they were less sure of themselves. The implication is that students may be driven by a general passion for sport more than a particular career goal. This may not be that unusual for undergraduate students, no matter their major. Indeed, the undergraduate experience is largely one of discovering what is available in the way of professional opportunities, and that is likely not any different for sport management students. But what this does indicate is that undergraduate students who choose to focus on sport management could benefit from intensive academic advising before launching into the degree program.

\section{Advising Newly Declared Majors}

The results of this study also reveal a gap between passion for a subject matter and knowing how to pursue that passion in the form of a long-lasting and rewarding career. Bridging the gap presents an advising challenge, especially if advisors are not well versed in the sport management job market or the requirements of sport-related jobs. In the case of parks, recreation, and tourism advisors, it is incumbent on them to do their homework if they are to offer sound academic and career counseling to sport management students. Advisors may want to emphasize connecting with people already working in the sport management field to gain a better idea of the job market, and what courses, internships, or other experiences are beneficial for sport management students when pursuing employment.

It is also interesting to note that even though the sport management students surveyed reported by a $58 \%$ to $42 \%$ margin that "playing sports" was more important to U.S. culture than "watching sports," students overwhelmingly wanted to work on the "sport as entertainment" side of the industry. This emphasis on "playing sports" was even more strongly seen in students who responded that they had been very active in sports participation (61\% also stating that playing sports was more important) and students who said their identity was completely wrapped up in sports (68\% also stating that playing sports was more important). This seeming incongruity offers a teachable moment for academic advising and classroom discussion purposes. Why would sport management students not want to work in the context they deemed more important to the U.S. way of life? Are they unaware of the career opportunities on the "sport as participation" side of things? Are such jobs less lucrative in terms of salary or prestige? Or is it something else? As Edwards and Peachey (2010), Chalip (2009), and other sport management scholars have noted, this is a focal point around which faculty and students could discuss sport and recreation's potentially symbiotic relationship. Holding such a conversation with sport and recreation students could help all involved understand the similarities between the emphasis areas and begin the process of building departmental cohesion.

\section{Curricular Implications}

A main purpose of this study was to consider how to address the uneasy fit that can exist when sport management and parks, recreation, and tourism students are housed in the same department. Sport scholars have debated whether sport management belongs in departments of business or those related to sport studies (Costa, 2005). As noted, respondents in this study have an identity very much wrapped up in sports. Yet almost three-quarters (70\%) of respondents also agreed that sport is a specialization within recreation. Under the circumstances, it seems logical to assume they would be receptive to an education focused on general management principles and practices that they, in turn, could apply to sport contexts. Yet a long history of course evaluations, sport management student feedback, and anecdotal faculty comments suggests otherwise (Dustin \& Schwab, 2008a, 2008b). 
The most salient data to help answer this question are the results demonstrating the strong degree to which sport management students identify with sport. As previously noted, $96 \%$ of students were either "active" (18\%) or "very active' (78\%) in playing sports during their formative years, $78 \%$ identified as "die-hard" sports fans, and $79 \%$ said their identities were wrapped up in sport "a lot" (55\%) or "completely" (24\%). Put simply, sport management students care deeply about sport.

The implication related to departmental fit may be that the specific department may not matter that much to students. Undergraduates appear to choose their major because of an interest and involvement in sport as a general construct rather than because of a specific interest in sport business, sport recreation, or sport administration. Additionally, it is worth noting that a majority of sport management students (from parks, recreation, and tourism departments) do not end up in a sport-related job at all (Timmerman, Schwab, Wells, \& Dustin, 2012). It is, therefore, important for students to learn a variety of skills applicable to many future job opportunities. Thus, a department that uses sport as a vehicle to discuss and explain concepts in business, public administration, exercise science, law, and other areas would not only match students' interests in sports, but would also contribute to the development of a number of applicable job skills.

This suggestion may conjure up images of a "Department of Sport," which is likely to be rejected for its silo effect, or as being simply impractical. A more reasonable conclusion, however, is that faculty members should ensure that students are able to relate concepts and make practical applications to the world of sport, while also providing some courses specific to sport management students. This approach would be no different than what parks, recreation, and tourism departments currently do for students with a therapeutic recreation interest, or business schools do for students with a marketing interest. In a study of Australian students, for example, Sibson (2010) found that in order for students to illustrate readiness to work in a chosen field, they must first demonstrate a sound understanding of how general principles can be applied in practice. Once general principles are understood, professors can provide opportunities for students to focus on their personal interests or career goals within small group projects or individual work. Providing assignments in which students can find personal relevance with the material will help solidify both the conceptual and practical sides of a topic.

Finally, the results of this study lend further support to the idea that an undergraduate education should do more than prepare students for a job - it should prepare them to participate in, and contribute to, their society. More than half (54\%) of the sport management students who responded to the survey felt sport was a critical source of social and cultural identity. Given the increasing prominence of sport in our culture, especially the rise of spectator sport, and all its associated social, cultural, economic, and political ramifications, the college classroom is the ideal place for students of all persuasions to discuss and debate the role of sport in the U.S., not as part of their professional preparation necessarily, but in preparation for their upcoming role as enlightened citizens in a participatory democracy (Dustin \& Schwab, 2010).

\section{Employment Implications}

Notwithstanding the importance of a general education, the goal of a higher education for most students is to be competitive in the job market. Several researchers have addressed the dearth of available careers in sport management (Branch, 2002; Edwards \& Peachy, 2010; Gibson, 2008; Parkhouse \& Pitts, 2005), especially positions in sport as entertainment (Weese, 2002). Yet the results of this survey indicate that most sport management students aspire to work in sport as entertainment, though their specific career goals are ill-defined. In a parallel survey recently completed by Timmerman, Schwab, Wells, and Dustin (2012), results suggested that only about twothirds of sport management graduates ended up working in sport, and that after a period of time that 
number was reduced to one-third. That survey also indicated that fewer than $15 \%$ of the respondents ended up working in parks, recreation, or tourism settings. Respondents remaining in the sport industry, even those leaving for more lucrative careers, reiterated their love for sport as a primary motivation for staying in the field.

The sport management job market is clouded by a number of factors. It is unclear whether a graduate education, law degree, an MBA, or some other professional degree is necessary to succeed in sport management. It is also unclear just how important internships and professional networking are to get one's foot in the door. Given the strong interest in athletic administration among respondents, it is telling that in a recent study by Schneider and Stier (2005), $90 \%$ of the presidents of Division I, II, and III colleges and universities considered a master's degree essential, including a mastery of budgeting and finance. Sport management students should be aware of this early in their undergraduate studies.

One inference from this study is the importance of supporting students' career paths so they follow their educational interests as well as thinking realistically about future career options. Given that students are likely to be more successful in a career that matches their personality and that the respondents in this study said their identity was largely wrapped up in sports, academic advisors should counsel students to follow their passion. However, as many sport careers require a graduate education, students should also be advised about the realities of securing their perfect job upon graduation. Given the tight job market, the significance of internships, personal contacts, professional networking, and the possible need for graduate education, it is critical that sport management students are aware of what it takes to be successful after graduation. Parks, recreation, and tourism educators who advise sport management students are obliged to educate themselves about all the factors that lead to gainful employment. This may take more work on the part of advisors and faculty members, but the effort is well worth it if students are better armed with the information necessary to make career choices that will lead to greater work-life satisfaction.

\section{Limitations and Recommendations}

The survey results reported here are based on a sample of 434 self-selecting respondents to an online survey sent to 1,337 currently enrolled undergraduate sport management majors across seven universities. The reporting and interpretation are based on the assumption that those 434 respondents are not significantly different from the survey recipients who chose not to respond. Our confidence in the validity of the results is heightened by the similarities (save for one item) found across all seven participating universities. Those results provided a clear picture of sport management students, how they found out about their college major, what their career aspirations and goals were, how they saw the role of sport in U.S. life, and how they viewed the relationship between sport and recreation.

Based on the results of this survey, several researchable questions arise for faculty members in departments of parks, recreation, and tourism who offer sport management as part of their curricular offerings. Given their love for sport, how can advisors best counsel sport management students about finding a career in sport? Given the differences between "sport as participation" and "sport as entertainment," what are the curricular implications for professional preparation? Given sport and recreation's common academic heritage, what are the most effective ways to teach sport and recreation students together? Finally, given the increasingly prominent role of sport in U.S. culture, what are the best conversations to have between sport management students and their peers in parks, recreation, and tourism that can lead to mutual respect and understanding as well as building a sense of common cause that results in a more collaborative working relationship? 


\section{Conclusion}

The results of this study provide a basic understanding of sport management students within departments of parks, recreation, and tourism, and offer insights for faculty teaching various groups of students in such departments. As sport management students continue to increase in number, it is necessary that professors persist in investigating not only how to best serve their students' varied interests within one academic home, but also how the fundamental similarities among sport, parks, recreation, and tourism can provide opportunities for cohesion rather than conflict in their departments.

\section{References}

Branch, D. (2002). Sport Marketing Quarterly: A journal designed for the business of marketing sport. Sport Marketing Quarterly, 11(2), 80-83.

Chalip, L. (2009). Kirtland's warbler vs. brown-headed cowbird: The recreation and sport management debate. Butler Lecture at the Annual Conference of the National Recreation and Park Association, October, Salt Lake City, Utah.

Chalip, L., Schwab, K., \& Dustin, D. (2010). Bridging the sport and recreation divide. Schole, 25, 1-10.

Costa, C.A. (2005). The status and future of sport management: A Delphi study. Journal of Sport Management, 19, 117-142.

David, M., \& Sutton, C. (2004). Social Research: The Basics. Thousand Oaks, CA: Sage Publications, Inc.

Dillman, D., Smyth, J., \& Christian, L. (2009). Internet, mail, and mixed-mode surveys: The tailored design method ( $3^{\text {rd }}$ ed.). Hoboken, NJ: John Wiley \& Sons, Inc.

Dustin, D., \& Schwab, K. (2010). Watching life pass us by. UTAH Leisure Insights, 30(2), 8-9.

Dustin, D., \& Schwab, K. (2008a). Consider the Kirtland's Warbler. Schole, 23, 1-8.

Dustin, D., \& Schwab, K. (2008b). Reflections on inter-species parasitism: A rejoinder to Gibson, Howard, McDonald, Wellman and Rea." Schole, 23, 23-26.

Edwards, M., \& Peachey, J. (2010). Irreconcilable differences or vibrant habitat? An examination of sport management's perceived invasion of recreation's nest. Sport Management Education Journal, 4, 18-30.

Gibson, H. (2008). Comment on Dustin and Schwab article "Consider the Kirtland's Warbler." Schole, $23,17-20$.

Holland, J. (1973). Making vocational choices: A theory of careers. Englewood Cliffs, N.J.: PrenticeHall.

Howard, D. (2008). Comment on Dustin and Schwab article "Consider the Kirtland's Warbler." Schole, 23, 13-16.

McDonald, C. (2008). Comment on Dustin and Schwab article "Consider the Kirtland's Warbler." Schole, 23, 21-22.

Mahony, D. (2008). No one can whistle a symphony: Working together for sport management's future. Journal of Sport Management, 22, 1-10.

Nicademus, K. (2012). Personality type and job satisfaction. In R. Urman \& J. Ehrenfeld (Eds.), Physicians' pathways to non-traditional careers and leadership opportunities. New York: Springer.

North American Society for Sport Management, (2012). Retrieved from http://www.nassm.com/ InfoAbout/SportMgmtPrograms.

Parkhouse, B., \& Pitts, B. (2005). History of sport management. In B. Parkhouse (Ed.) The management of sport: Its foundation and application ( $4^{\text {th }}$ Edition, pp. 2-14). New York: McGraw Hill. 
Schneider, R., \& Stier, W. (2005). Necessary education for the success of athletics directors: NCAA presidents' perceptions. The Sport Journal, 8(1). Retrieved from http://www.thesportjournalorg/ article/necessary-education-success-athletics-directors-ncaa-presidents-perceptions

Sibson, R. (2010). Why event, sport and recreation management? A western Australian study of undergraduate student degree choice. Annals of Leisure Research, 13(3), 376-394.

Timmerman, D., Schwab, K.A, Wells, M.S., \& Dustin, D.L. (2012). Career paths in sport management. Research presentation delivered at the California Parks and Recreation Society Leisure Research Symposium, Long Beach, California, March 22.

Weese, W. (2002). Opportunities and headaches: Dichotomous perspectives on the current and future hiring realities in the sport management academy. Journal of Sport Management, 16 (1), 1-17.

Wellman, D., \& Rea, P. (2008). Comment on Dustin and Schwab article "Consider the Kirtland's Warbler." Schole, 23, 9-12. 